This is the pre-peer reviewed version of the following article:

Mingorance A., Xie H., Kim H.-S., Wang Z., Balsells M., Morales-Melgares A., Domingo N., Kazuteru N., Tress W., Fraxedas J., Vlachopoulos N., Hagfeldt A., Lira-Cantu M.. Interfacial Engineering of Metal Oxides for Highly Stable Halide Perovskite Solar Cells. Advanced Materials I nterfaces, (2018). 5. 1800367: - . 10.1002/admi.201800367,

which has been published in final form at https://dx.doi.org/10.1002/admi.201800367. This article may be used for non-commercial purposes in accordance with Wiley Terms and Conditions for Use of Self-Archived Versions. 
Table of Content

Metal oxides applied as transport layers in Perovskite Solar Cells provide enhanced efficiency and improved performance in long timescales operating solar cells. Interfacial engineering of oxides can be made through organic molecules with different anchoring groups which passivate traps and reduce hysteresis. Oxides can also be employed as highly conductive electrodes when doped, or as oxide/oxide bilayers enhancing device lifetime.

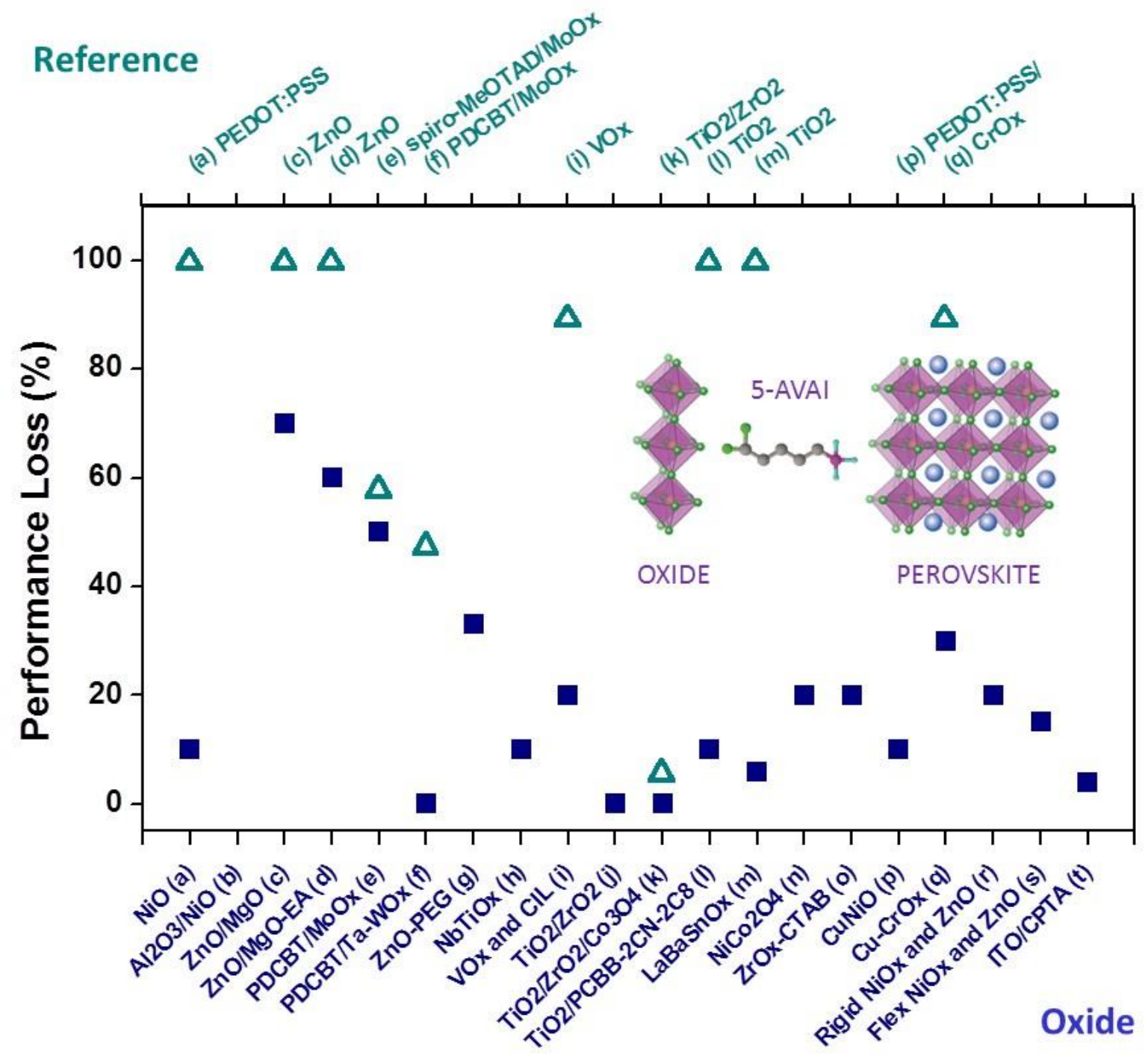




\title{
Interfacial Engineering of Metal Oxides for Highly Stable Halide Perovskite Solar Cells
}

Alba Mingorance ${ }^{1,}$ Haibing Xie ${ }^{1}$, Hui-Seon Kim ${ }^{2}$, Zaiwei Wang ${ }^{2}$, Marc Balsells $^{1}$, Anna Morales-Melgares ${ }^{1}$, Neus Domingo ${ }^{1}$, Nonomura Kazuteru ${ }^{2}$, Wolfgang Tress ${ }^{2}$, Jordi Fraxedas ${ }^{1}$, Nick Vlachopoulos, ${ }^{2}$ Anders Hagfeld ${ }^{2 *}$ and Monica Lira-Cantu ${ }^{1 *}$

1. A. Mingorance, Dr. H. Xie, M. Balsells, A. Morales, Dr. N. Domingo, Dr. J. Fraxedas, Prof. M. Lira-Cantu Catalan Institute of Nanoscience and Nanotechnology (ICN2), CSIC and the Barcelona Institute of Science and Technology (BIST), Campus UAB, Bellaterra, 08193 Barcelona (ES).

E-mail: monica.lira@icn2.cat

2. Z. Wang, Dr. H.-S. Kim, Dr. N. Kazuteru, Dr. W. Tress, Prof. N. Vlachopoulos, Prof. Anders Hagfeldt Laboratory of Photomolecular Science, Institute of Chemical Sciences and Engineering, Ecole Polytechnique Fédérale de Lausanne, CH-1015 Lausanne, Switzerland

E-mail: anders.hagfedlt@epfl.ch

Keywords: halide perovskite solar cells, self-assembly monolayers, functionalization, interfacial engineering, stability, metal oxides

\begin{abstract}
Oxides employed in halide perovskite solar cells (PSCs) have already demonstrated to deliver enhanced stability, low cost and the ease of fabrication required for the commercialisation of the technology. The most stable PSCs configuration, the carbon-based hole transport layerfree PSC (HTL-free PSC), has also demonstrated a stability of more than one year of continuous operation partially due to the dual presence of insulating oxide scaffolds and conductive oxides. Despite these advances, the stability of PSCs is still a concern and a strong limiting factor for their industrial implementation. The engineering of oxide interfaces functionalized with molecules (like self-assembly monolayers, or SAMs) or polymers results in the passivation of defects (traps) at the interface, providing numerous advantages such as the elimination of hysteresis and the enhancement of solar cell efficiency. But most important is the beneficial effect of interfacial engineering on the lifetime and stability of PSCs. In this work, we provide insight into the recent developments reported on the surface
\end{abstract}


functionalization of oxide interfaces in PSCs with emphasis on the effect of device stability. We also discuss the different binding modes, their effect on defect passivation, band alignment or dipole formation, and how these parameters influence device stability.

\section{Introduction}

Over the past few years, halide perovskite solar cells (PSCs) have been demonstrated to be a strong competitor in the photovoltaic arena; their power conversion efficiency, right now at $23.3 \%$ (certified) ${ }^{[1]}$ has become strong and steady in only a few years. The technology applies inexpensive, light-harvesting perovskite-type minerals, has a straightforward design and composition of derivatives, and utilises facile solution-based processing methods. ${ }^{[2]}$ Another advantage of PSCs is their potential to be fabricated as flexible and semi-transparent lightharvesting arrays possessing polychromic sensitivity. However, there is an urgent need to improve their long-term stability before their commercial potential can be realised. ${ }^{[2]} \mathrm{We}$ can differentiate diverse degradation factors for PSCs for example, light, atmosphere, moisture and temperature (LAMT), followed by intrinsic and extrinsic factors. ${ }^{[2]}$ LAMT are wellknown and studied degradation factors that can dramatically affect halide perovskite materials. Intrinsic factors influence the physical and chemical properties of materials in device components, such as the halide perovskite active layer, barrier layers or electrodes, as well as their interfaces. Other stability issues may affect physical properties related to crystallinity, morphology or intrinsic ionic drift defects. Extrinsic factors affect the entire device for example, device configuration, fabrication methods, additives and solvents applied or encapsulation. As intrinsic factors, novel materials, such as wide-band gap semiconductor oxides, have recently become the focus of extensive research due to the high stability properties that they can confer to the PSCs. Oxides are an important part of PSCs, are abundant in nature and are very versatile materials. Many of their chemical and physical properties can be modified by the introduction 
of imperfections into their crystalline structure. The presence of dopants, defects or nonstoichiometry can induce variations in the oxide properties and significantly alter the final device performance ${ }^{[3]}$ Research on different interfacial organic modifiers has gained attention due to their ability to influence oxide properties, tune their electrical, chemical and physical properties, affect charge carrier dynamics (transport, injection and recombination) or modify their work function. Other benefits of applying surface modifiers in PSCs are, for example, the enhancement of moisture tolerance, ${ }^{[4]}$ the suppression of hysteresis, ${ }^{[5]}$ the enhancement of power conversion efficiency

and lifetime stability ${ }^{[6]}$; moreover, the enhancement of the fracture resistance of perovskite films can be reinforced with the aid of organic or polymeric modifiers. ${ }^{[7]}$

Defects in semiconductor materials applied in PSCs can behave as traps for charge carriers, reducing the performance of solar cells. ${ }^{[8]}$ Traps can be found both within the bulk of the material and at interfaces where most of the photovoltaic losses are found in a complete solar cell device. In a PSC, interfaces can limit solar cell performance for example, the interface between the transport layers (hole transport layer, HTL or electron transport layer, ETL) and halide perovskite, the interface between electrodes (back metal electrodes or the fluor tin oxide, FTO, electrode) and transport layers, or the interface between grains of the halide perovskite semiconductor itself. Some literature reviews have focused on traps found in different materials and interfaces ${ }^{[8]}$ most of them are focused on the effect on device performance (efficiency, hysteresis). Documents analysing the effect of traps on the long-term stability of PSCs are rare. A recent report analysed the trap passivation at interfaces via molecular functionalization and the beneficial effect on PSC stability. ${ }^{[9]}$ Improvement was observed independent of the type of PSC configuration, the type of molecular modifier applied, the PSC interface being functionalized, or the type of stability test performed ${ }^{[9]}$. Oxides in PSCs play an important role in device stability. The most efficient PSCs are based on the normal configuration mesoscopic 
$\mathrm{TiO}_{2}$ or planar $\mathrm{SnO}_{2}$, and the most stable PSCs (fabricated by screen printing) are based on trilayers of mesoporous $\mathrm{TiO}_{2} / \mathrm{ZrO}_{2} /$ carbon, demonstrating more than $10,000 \mathrm{~h}$ of lifetime stability. ${ }^{[10]}$ In all these cases, oxides provide higher stability when compared to organic semiconductors, but also trap passivation in these oxides also benefits solar cell lifetime. Figure 1 shows some examples of the different approaches for the application of oxides in PSCs to promote device stability. Six general trends are observed: (1) the replacement of organic semiconductors (e.g. poly(3,4ethylenedioxythiophene) polystyrene sulfonate, PEDOT) by oxides (Figure 1a and 1p), (2) the application of doped oxides (Figure 1f, 1h, 1n, 1p, 1q), (3) the application of ternary oxides (Figure $1 \mathrm{~m}$ ), (4) the application of double oxide layers (Figure 1b, 1c, 1d, 1j, 1k), (5) the application of oxides as both the ETL and the HTL (Figure 1e, 1f, 1r, 1s), and (6) the functionalization of the oxide interface with organic molecules (Figure 1d, 1e, 1f, $1 \mathrm{~h}, 1 \mathrm{k})$. In all cases, the substitution of organic semiconductors by metal oxide layers or the interface engineering of the oxide results in the enhanced stability of the PSCs. Among them, trap passivation via the functionalization of the oxide surface with organic modifiers is a promissing approach due to the great variety of functional groups encountered in organic modifiers and the vast amount of oxides and their surface qualities. 


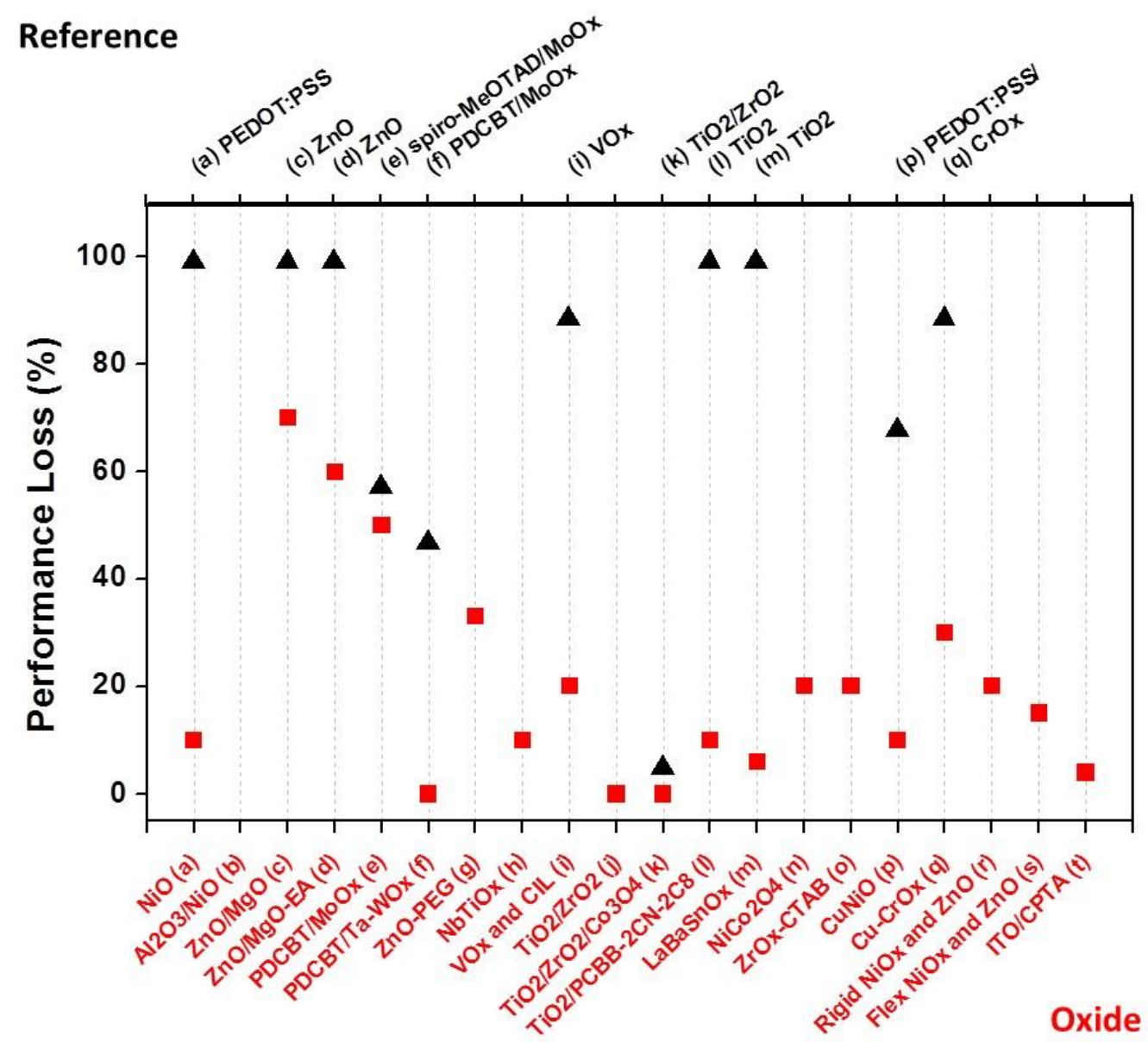

Figure 1. Stability of perovskite solar cells applying metal oxides. Efficiency loss (\%) observed after stability analysis for perovskite solar cells applying metal oxides (red squares) and the comparison to its reference device (black triangles). Different stability test performed for each case. The configuration of the corresponding perovskite solar cell are: (a) ITO/NiOx/

Perovskite / $\mathrm{ZnO} / \mathrm{Al} \quad$ and ITO/PEDOT:PSS/Perovskite/ PCBM/Al [11]; $\mathrm{FTO} / \mathrm{TiO}_{2} / \mathrm{mpTiO}_{2} / \mathrm{Al}_{2} \mathrm{O}_{3} / \mathrm{NiO} / \mathrm{MAPbI}_{3-\mathrm{x}} \mathrm{Cl}_{\mathrm{x}}-\mathrm{NiO} /$ Spiro-OMeTAD/Au; ${ }^{[12]}$ FTO/ZnO/Perovskite/SpiroOMeTAD/Au and FTO/ZnO/MgO/Perovskite/Spiro$\mathrm{OMeTAD} / \mathrm{Au} ;{ }^{[13]}(\mathrm{d})$ FTO/ZnO/MgOEA/Perovskite/SpiroOMeTAD/Au; ${ }^{[13]}$ (e) $\mathrm{ITO} / \mathrm{C}_{60}-\mathrm{SAM} / \mathrm{SnO}_{x} / \mathrm{PC}_{60} \mathrm{BM} /$ Perovskite/ doped spiroMeOTAD/MoOx/Au and $\mathrm{ITO} / \mathrm{C}_{60}-\mathrm{SAM} / \mathrm{SnO}_{x} / \mathrm{PC}_{60} \mathrm{BM}$ /Perovskite/ PDCBT/MoOx/Au; ;14] (f) 
ITO/C $60-\mathrm{SAM} /$ Perovskite/PDCBT/MoOx/Au and ITO/C60-SAM/Perovskite/PDCBT/Ta$\mathrm{WO} x / \mathrm{Au} ;{ }^{[14]} \quad(\mathrm{g}) \quad$ ITO/ZnO/Perovskite/Spiro-OMeTAD/Au and ITO/ZnOPEG/Perovskite/Spiro-OMeTAD/Au; ${ }^{[15]}$

FTO/NiMgLiO $\times$ /Perovskite/PCBM/NbTiO $/$ /Ag

[16] (i) ITO/PEDOT:PSS/VO $/$ /Perovskite/PCBM/CIL/Ag and ITO/PEDOT:PSS/VO ${ }_{\mathrm{x}} /$ Perovskite/PCBM/Ag; ${ }^{[17]}$ (j) FTO/TiO $/ \mathrm{ZrO}_{2} /$ Carbon with infiltrated 2D:3D Perovskite; ${ }^{[10]}$ (k) FTO/TiO $/ 2 / \mathrm{ZrO}_{2} /$ Carbon and $\mathrm{FTO} / \mathrm{TiO}_{2} / \mathrm{ZrO}_{2} / \mathrm{Co}_{3} \mathrm{O}_{4} /$ Carbon with infiltrated Perovskite; ${ }^{[18]}$ (1) Glass/ITO/TiO 2 / PCBB-2CN-2C8/ Perovskite/spiro-OMeTAD/Au; ${ }^{[19]}$ (m) FTO/LaBaSnO $3 /$ Perovskite/PTAA/Au and $\quad \mathrm{FTO} / \mathrm{TiO}_{2} /$ Perovskite/PTAA $/ \mathrm{Au} ;{ }^{[20]}$ (n) $\mathrm{ITO} / \mathrm{NiCo}_{2} \mathrm{O}_{4} /$ Perovskite/PC ${ }_{61} \mathrm{BM}: \mathrm{C}_{60} / \mathrm{ZrAcac} / \mathrm{Ag}$; ${ }^{[21]}$ (o) ITO/PEDOT:PSS/Perovskite/PC ${ }_{61} \mathrm{BM} / \mathrm{ZrOx} / \mathrm{Ag}$ and ITO/ PEDOT:PSS/Perovskite/PC 61 BM/ZrOx-CTAB/Ag; ${ }^{[22] ~(p) ~ I T O / P E D O T: P S S / ~}$ Perovskite/PCBM/C $60 / \mathrm{Ag}$ and ITO/CuNiO/Perovskite/PCBM/C $60 / \mathrm{Ag} ;{ }^{[23]}$ (q) FTO/CrOx/ Perovskie/ PCBM/Ag and FTO/Cu-CrOx/Perovskie/PCBM/Ag; ${ }^{[24]}$ (r) rigid Glass/ITO/ $\mathrm{NiOx} \cdot \mathrm{np} / \mathrm{Perovskite/PCBM} / \mathrm{ZnO} \cdot \mathrm{np} / \mathrm{Al} ;^{[25]}$ (s) flexible $\mathrm{PEN} / \mathrm{ITO} / \mathrm{NiOx} \cdot \mathrm{np} / \mathrm{Perovskite}$ $/ \mathrm{PCBM} / \mathrm{ZnO} \cdot \mathrm{np} / \mathrm{Al} ;{ }^{[25]} \quad$ (t) $\quad$ ITO/PCBM/Perovskite/Spiro-OMeTAD/Au and ITO/CPTA/Perovskite/Spiro-OMeTAD/Au. ${ }^{[26]}$ ITO: Indium tin oxide; MA: methyl ammonium; PCBM: phenyl-C 61 -butyric acid methyl ester; Spiro-OMeTAD: $\mathbf{N}^{2}, \mathbf{N}^{2}, \mathbf{N}^{2}, \mathbf{N}^{2}, \mathbf{N}^{7}$, $\mathbf{N}^{7}, \mathbf{N}^{7^{\prime}}, \mathbf{N}^{7^{\prime}}$ - octakis (4-methoxyphenyl) - 9,9'-spirobi [9H-fluorene] - 2,2',7,7' - tetramine; EA: ethylene amine; PDCBT: poly[5,5'-bis(2-bu-tyloctyl)-(2,2'-bithiophene)-4,4'-dicarboxylate-alt-5,5'2,2'bithiophene]; PEG: Poly ethylene glycol; CIL: Diethanol amine; PCBB-2CN-2C8: [6,6]PhenylC61-butyric Acid-dioctyl-3,3'-(5-hydroxy-1,3-phenylene)- bis(2-cyanoacrylate)ester; PTAA: poly[bis(4-phenyl)(2,4,6-trimethylphenyl)amine]; ZrAcac: zirconium(IV) acetylacetonate; CETAB: cetyltrimethylammonium bromide; PEN: Polyethylene naphthalate; CPTA: $\mathrm{C}_{60}$ pyrrolidine tris-acid. Updated Graph from [27]. 
Typically, organic modifiers applied in PSCs consist of one or two terminal groups. If the organic modifier is anchored to a surface to form a well-organised layer, it is known as a selfassembled monolayer (SAM), and typically consists of an anchoring group (or head group), a linkage, and a functional group (or terminal group). Independent of the type of organisation on the surface, the organic modifier can be selected among different anchoring and functional groups, of different structure and length of the linkage body. The dual functionalization of organic modifiers permits different binding strengths between the oxide and the halide perovskite. Binding can be made via chemical bonds (covalent, ionic, hydrogen, coordination, etc.), as will be discussed in the following section.

\section{Oxide Surface Modification Modes}

Many oxides share surface-bound - $\mathrm{OH}$ groups as anchoring sites that favour functionalization with organic molecules. Zuihof, et al., indicated that in some cases, activation of the oxide surface is required, which in turn allows for the use of a wide range of attachements chemistries. ${ }^{[28]}$ Recent published work, has reviewed the different attachments chemistries possibles to covalently bond organic monolayers onto oxides. Figure 2 summarises some of these different attachment methods and the resulting modified oxide surfaces. Silanes and carboxylates are the most studied due to the environmental friendliness of carboxylic acid and the ease of reaction of silanes. ${ }^{[28]}$ Nevertheless, more stable monolayers can be obtained by the application of phosphonates or chatecols, among others. Zuihof et al. has recently reviewed the possible covalent attachments of organic molecules on oxide surfaces. ${ }^{[28]}$ Six different attachment chemistries are described: silanes, phosphonates, carboxylates, catechols, alkynes and alkenes and amines (Figure 2). Each of these shows different strengths of interaction with the oxide. The final successful functionalization of an oxide substrate with organic molecules 
will depend not only on the quality and reactivity of the functional groups, but also on the nature of the oxide surface. In any case, reaction conditions such as temperature, $\mathrm{pH}$, solvent or thermal annealing are of enormous relevance. In PSCs, four functional groups (silane, carboxylate, amine and, more recently, phosphonic) are the most applied when selecting an organic molecule or polymer for interfacial modification (Table 1). In PSCs, the careful selection of the organic molecule and its terminal groups is of paramount importance since it will determine both the molecule-oxide interaction and the moleculehalide perovskite interaction. A brief description of some of these functional groups (shown in Figure 2) is described below:

- Phosphonates. Phosphonic acids $\left[\mathrm{R}-\mathrm{PO}_{3} \mathrm{H}_{2}\right]$ and phosphonate ester derivatives $\left[\mathrm{RPO}_{3} \mathrm{R}_{2}\right]$ (where $\mathrm{R}=$ alkyl or aryl) can easily react and self-assemble onto oxide surfaces. The quality of the binding depends on many reaction conditions, but a wide variety of solvents are allowed, including water. ${ }^{[28]}$ Lewis acidic metal oxides allow for stronger $\mathrm{P}-\mathrm{O}-\mathrm{M}$ binding of the phosphoryl oxygen atom $(\mathrm{P}=\mathrm{O})$ on the oxide surface than those metal oxides without Lewis acidity. In the first case, heterocondensation with the $-\mathrm{OH}$ group of the oxide is possible, resulting in covalent binding.

- Carboxylates. In solar cells, binding organic molecules with carboxylic acid functional groups to a metal oxide surface is a well-known process and the principle behind the anchoring of dyes into $\mathrm{TiO}_{2}$ in dye sensitized solar cells (DSSC). ${ }^{[29]}$ This type of bonding is the oldest and most studied kind. Several binding modes are possible through the outer-sphere or inner-sphere adsorption complexes, such as electrostatic attraction, $\mathrm{H}$ bond to bridging oxygen, H-bonds to carboxylic oxygen, monodentate (metal-ester), bidentate bridging or bidentate chelating. Several reviews can be found in the literature on this topic. ${ }^{[28,30]}$

- Silanes. Molecules with this functional group are characterised by the ease of reaction with $-\mathrm{OH}$ in oxides, which results in a strong covalent bond. This covalent bond 
stabilises the interface and permits further chemical modification. ${ }^{[30]}$ The most appied are reagents based on alkoxysilane ( $\mathrm{QSi}$-OR, where $\mathrm{R}=$ alkyl), hydrogenosilane ( $\square \mathrm{Si}$ $\mathrm{H})$ or chlorosilane ( $\square \mathrm{Si}-\mathrm{Cl})$, among others. Alkoxy- and chlorosilanes react with the $\mathrm{OH}$ group of the oxide through condensation reactions.

- Amines. Binding amines to the $-\mathrm{OH}$ group of the oxides results in a weak interaction, in some cases even weaker (chemically and mechanically) than for alkylsilanes. Although it is possible to bind amines to oxides, in PSCs, molecules with this functional group are usually selected to bind with halide perovskite through a hydrogen (from the amine)-tohalogen (from the halide perovskite) interaction. ${ }^{[9]}$

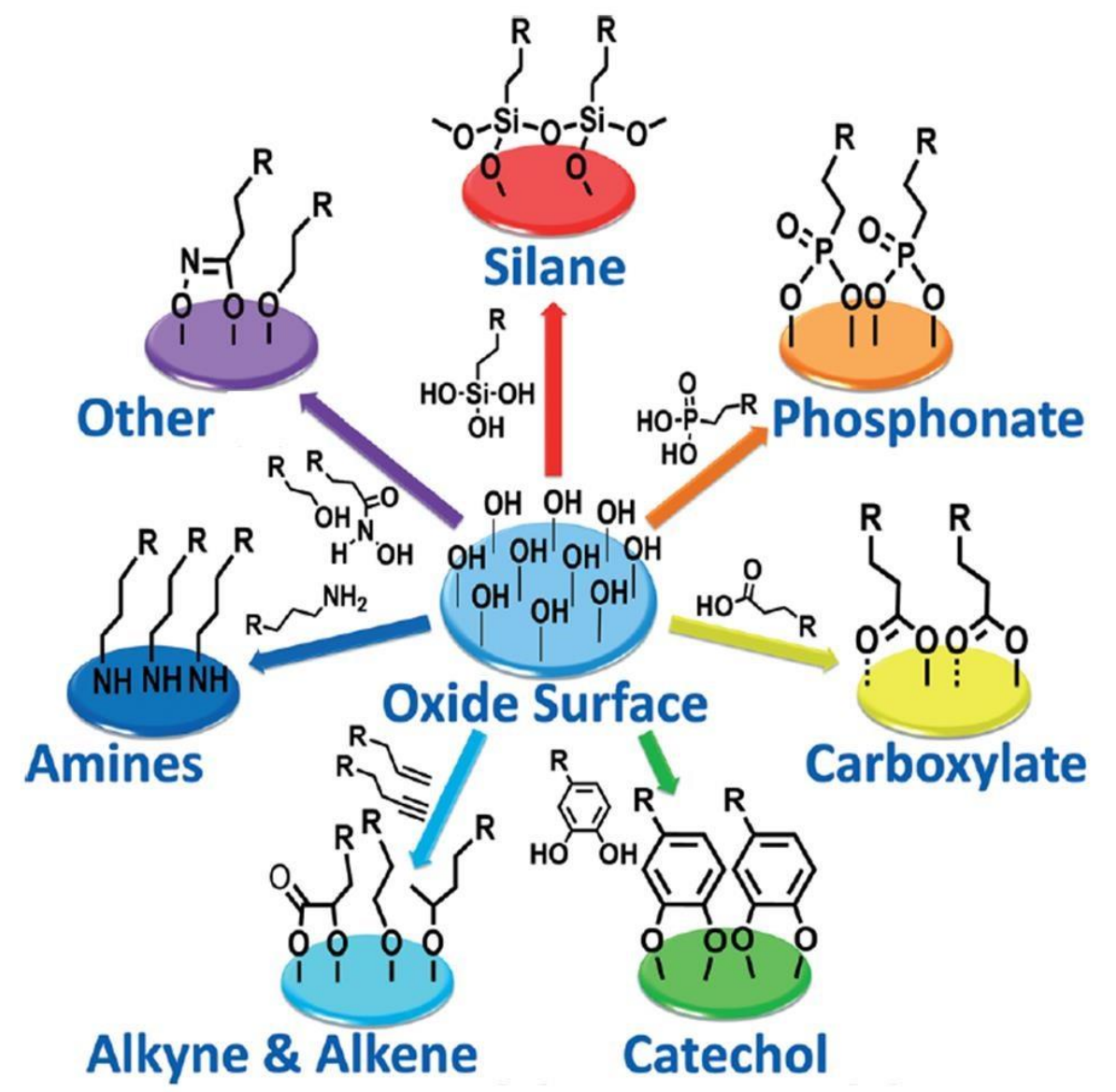

Figure 2. Attachment modes of organic molecules on oxide surfaces. Reproduced with permission. Copyright 2014, Wiley VCH. ${ }^{[28]}$ 
The most applied oxides in PSC can be found as nanostructured oxides (e.g. mesoporous $\mathrm{TiO}_{2}$ or $\mathrm{ZnO}$ nanorods) or as dense thin films (e.g. $\mathrm{SnO}_{2}$ ). Oxides can also be good electron or hole transport materials (e.g. $\mathrm{TiO}_{2}$ and $\mathrm{NiO}$ respectively), or can be insulators used as double oxide layers or scaffolds (e.g. $\mathrm{Al}_{2} \mathrm{O}_{3}, \mathrm{ZrO}_{2}$ or $\mathrm{SiO}_{2}$ ). They can be found as classical binary oxides, doped oxides, ternary oxides, or complex oxides with special functionalities (e.g. ferroelectricity, magnetism). ${ }^{[27,31-32]}$ The quality of the oxide surface is also of paramount importance for surface functionalization and final PSC stability. Surface reactivity depends on the oxide structure and composition, the number of defects or its crystallinity.

Past experience from DSSC for the attachment of dyes to the oxide surface gives us an indication of the relevance of $-\mathrm{OH}$ on the surface of the oxide, but it also reminds us of the importance of defects (e.g. oxygen vacancies, Vo). Oxygen vacancies can stabilise the adsorption of dyes and facilitate charge injection at the cost of lower open circuit voltage and higher electron-hole recombination rate ${ }^{[33]}$. An oxide chemical potential can also be modified with the introduction of oxygen vacancies or defects, and these are directly dependent on the type of oxide being applied. Greiner, et al. provided an illustrative example of the effect of the oxide quality. They introduced defects into two hole transport oxides, $\mathrm{NiO}$ and $\mathrm{MoO}_{3}$, and analysed how a molecule, N,N'-bis(1-naphtyl)-N,N'-diphenyl-1,1'-biphenyl-4,4'-diamine or $\alpha \mathrm{NPD}$, is adsorbed on their surface. $\mathrm{NiO}$ is known to form interstitial defects, while $\mathrm{MoO}_{3}$ forms oxygen vacancy defects. In order to increase the work function of $\mathrm{NiO}$, the oxide must be grown under oxidative conditions (oxygen atmosphere, high temperature, $\mathrm{O}_{3}$, etc.). In the case of $\mathrm{MoO}_{3}$, since its work function with respect to the molecule is too high (even for a defective oxide), it can only be decreased by annealing in a vacuum. ${ }^{[34]}$ A description of an universal energy-level alignment of organic molecules on metal oxides, which only depends on the electron-chemical-potential equilibrium, is described by the authors. ${ }^{[34]}$ Thus, the surface quality of the oxide, as well as the oxide characteristics, are of high relevance for the optimal 
anchoring of organic molecules without damaging the charge carrier dynamics and photovoltaic parameters of the final device.

\section{Functionalized Oxide Interfaces for Efficient Perovskite Solar Cells}

Table 1 shows some representative examples of the functionalization of PSC interfaces and its effect on solar cell efficiency and lifetime. Several methods for surface functionalization in PSCs can be applied, for example solution-assisted, vapor deposition or spin coating techniques. $^{[35]}$. The method employed for functionalization affects the strength or bonding of the molecule to the substrate. In some cases, thermal annealing permits the reinforcement of the anchoring between the molecule and the substrate.

The first and most important effect of the functionalization of interfaces is the enhancement of device efficiency. Yang Yang et al. have recently reported the application of SAMS with different functional groups anchored to the $\mathrm{SnO}_{2}$ oxide layer of planar PSCs. The molecules analysed were benzoic acid (BA) and dipolar interactions with the 4-pyridinecarboxylic acid (PA), 3-aminopropanoic acid (C3), 4-aminobenzoic acid (ABA), and 4-cyanobenzoic acid (CBA). Besides a reduction in the number of trap states, their results demonstrate that PSC performance shows the opposite trend to that of the energy level alignment theory as well as the importance of chemical interactions for device response. The use of the 4pyridinecarboxylic acid SAM resulted in PSCs with $18.8 \%$ power conversion efficiency or PCE (a 10\% enhancement compared to those without the organic modifier). ${ }^{[6]}$ Another work eliminated the application of $\mathrm{TiO}_{2}$ as an electron transport material and directly functionalized the conductive oxide electrode with a fullerene assembled monolayer. The fabrication of the monolayer was carried out at a low temperature, and the Sil- $\mathrm{C}_{60}-\mathrm{SAM}$ and showed that the functionalization was covalently attached to a clean, oxygen terminated surface of the FTO substrate. ${ }^{[36]}$ 
Table 1. Perovskite solar cells applying oxides and functionalized oxide interfaces.

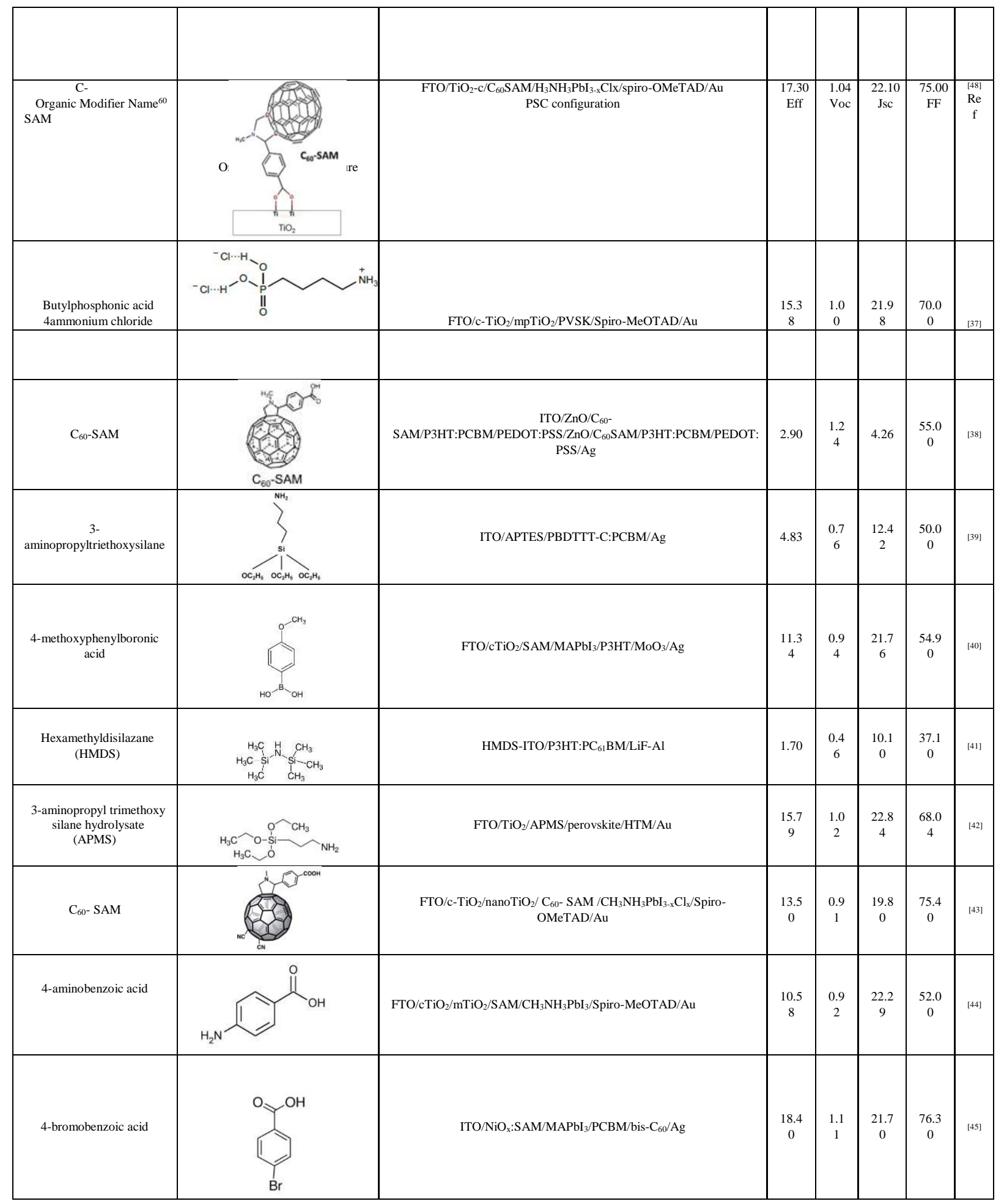




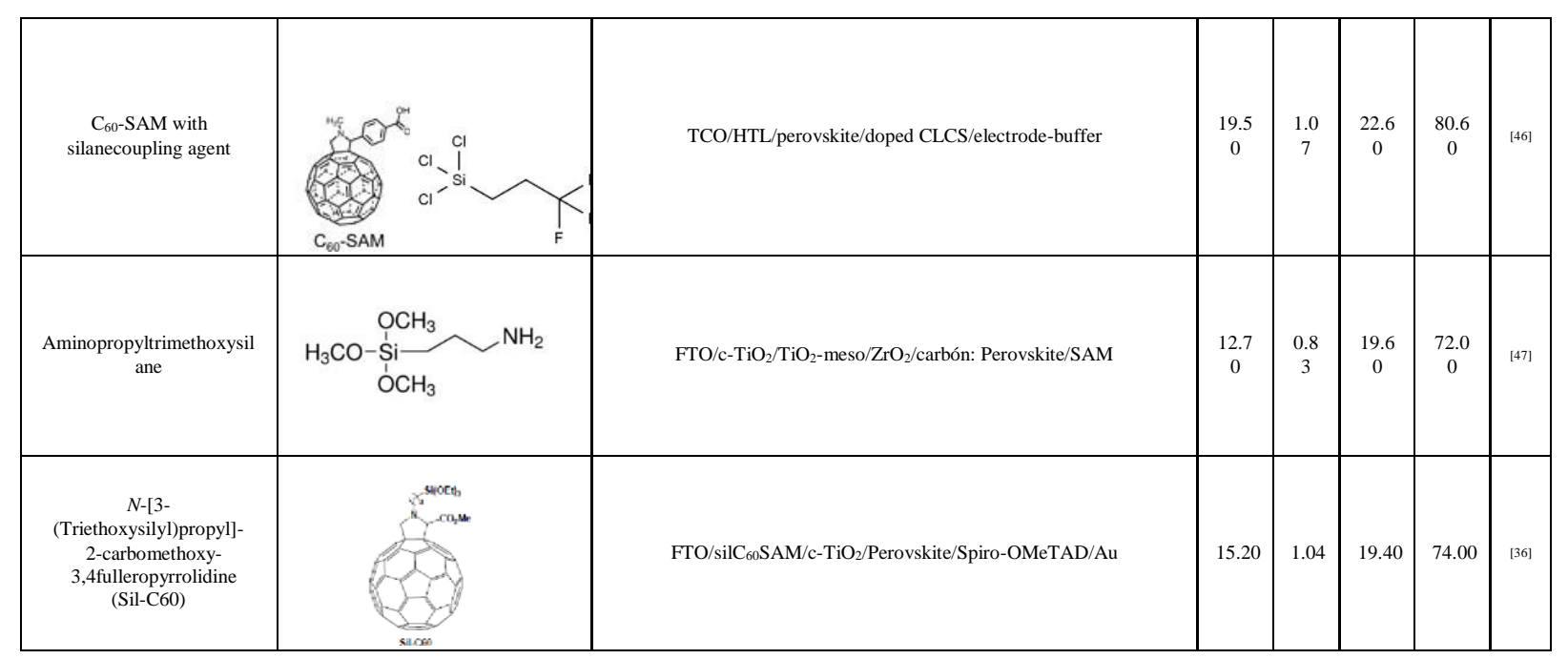

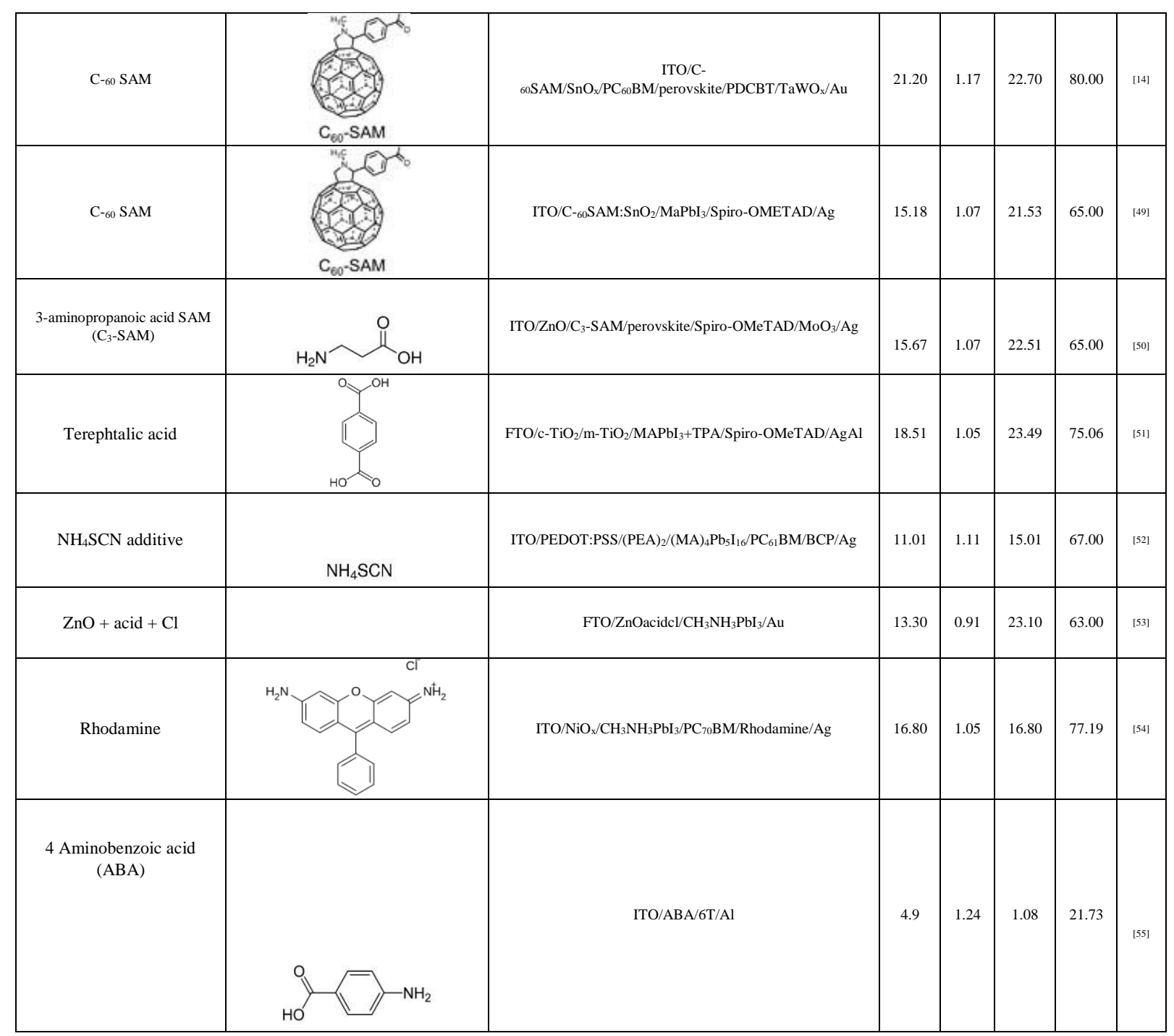




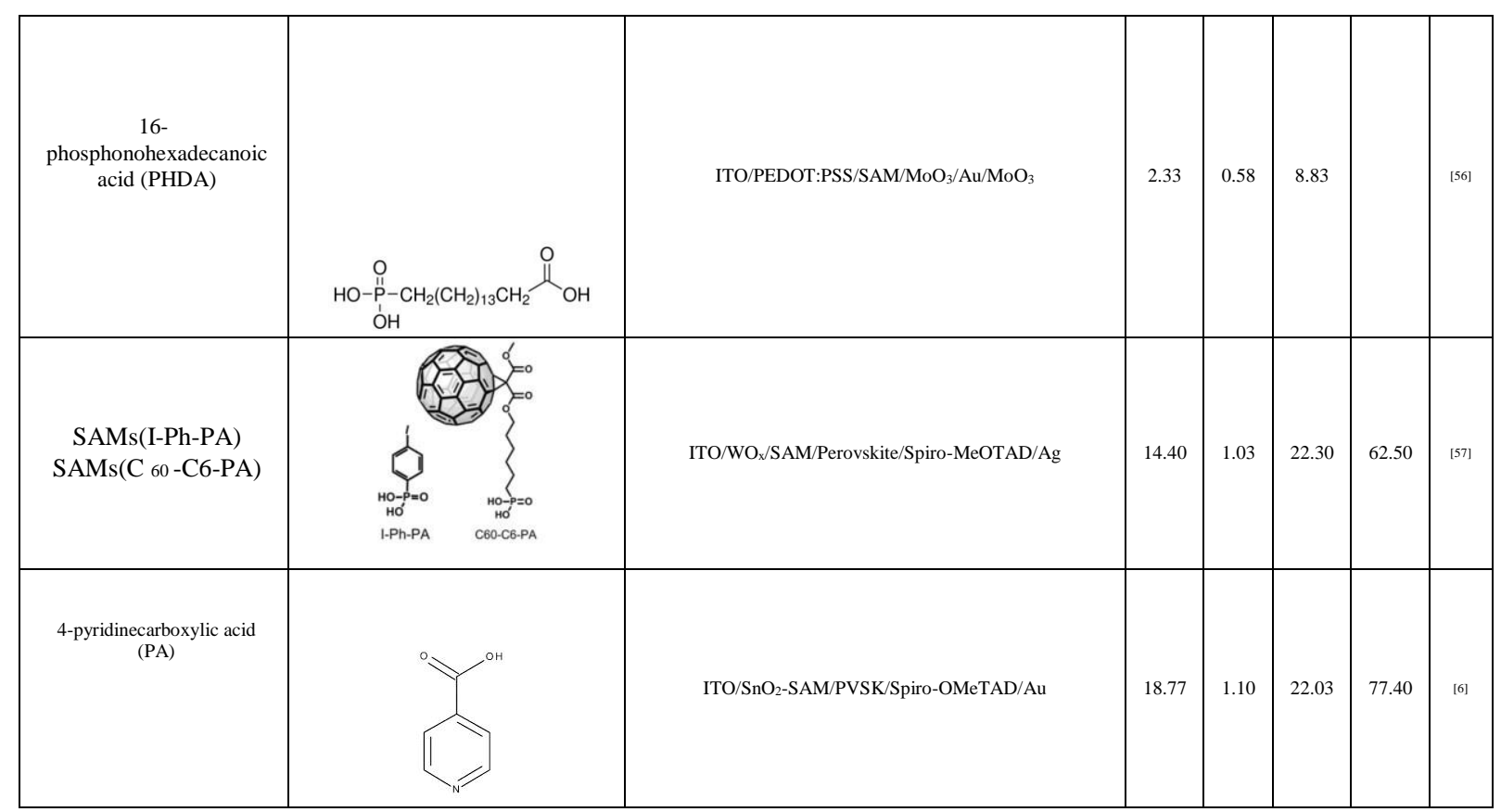

A technologically relevant PSC configuration is called the carbon-based HTL-free PSC. This PSC configuration employs a two-oxide layer, a $\mathrm{TiO}_{2}$ mesoscopic layer, and a second mesoscopic layer of an inert scaffold of $\mathrm{ZrO}_{2}$. The back electrode is made of a porous and conductive carbon paste. The halide perovskite is finally infiltrated into the $\mathrm{TiO}_{2} / \mathrm{ZrO}_{2} / \mathrm{C}$ trilayer structure. The application of insulating metal oxides as scaffolds in these C-based HTLfree PSCs made by printing methods (spraying and screen printing) is currently under intense investigation. Although the efficiency of the PSCs made by this method is not high (about $14 \%$ efficiency), ${ }^{[58]}$ the outstanding stability observed from these devices, recently reported at 10,000 $\mathrm{h},{ }^{[10]}$ makes the technology worthy of study. One key element for such outstanding stability seems to be related to the carboxylate bonding between the organic modifier (the aminovaleric acid, AVA) and the insulating scaffold, which can be found as a mesoporous layer of $\mathrm{Al}_{2} \mathrm{O}_{3}$ or $\mathrm{ZrO}_{2}$. Given the insulating nature of these oxides one can speculate whether oxides with more semiconducting properties could provide better efficiency without reducing device stability. In any case, different studies have demonstrated the possibility of attaching organic modifiers on insulating oxides and the effect on charge carrier dynamics. Durrant et al. recently reported on 
the growth of halide perovskite material within mesoporous $\mathrm{Al}_{2} \mathrm{O}_{3}$ oxide and the passivation effect on trap sites. ${ }^{[59]}$ They suggested that the passivation of traps originates via the reduction in the amount of exposed $\mathrm{Pb}$ ions (similar to a ligand-capped surface), as shown in Figure 3. The latter influences the growth of the halide perovskite crystallites, and is probably affected by the type of oxide and its acidity (higher acidity is found in silica than in $\mathrm{Al}_{2} \mathrm{O}_{3}$ ). Improved trap passivation is also observed at the perovskite $/ \mathrm{Al}_{2} \mathrm{O}_{3}$ interface in comparison with the perovskite $/ \mathrm{TiO}_{2}$ interface. ${ }^{[59]} \mathrm{ZrO}_{2}$ is another scaffold oxide applied in screen printing and highly stable C-based PSCs. Although its binding with the carboxylate of the AVA compound has been proposed to be responsible for enhanced stability, more studies are required to confirm the former. In this respect, Chen et al. studied the formation of a $\mathrm{ZrO}_{\mathrm{x}}$ doped with cetylammonium bromine, CTAB (Figure 1o). Halogen anions, such as bromine (Br), can preferentially substitute the oxygen sites and/or occupy oxygen vacancies, increasing conductivity and reducing traps. In this work the authors demonstrated how doping $\mathrm{ZrO}_{\mathrm{x}}$ with $\mathrm{CTAB}$ increases its electrical conductivity and improves device performance in comparison with devices applying the bare $\mathrm{ZrO}_{2}$ oxide.

Moreover, the $\mathrm{ZrO}_{\mathrm{x}}$-based material can be fabricated at room temperature, and the final device shows high stability without the need for rigorous encapsulation. ${ }^{[22]}$ All these novel results suggest that there is still much room for improvement in the functionalization of oxide interfaces, semiconductors or inert scaffolds, for the enhancement of stability in PSCs. 

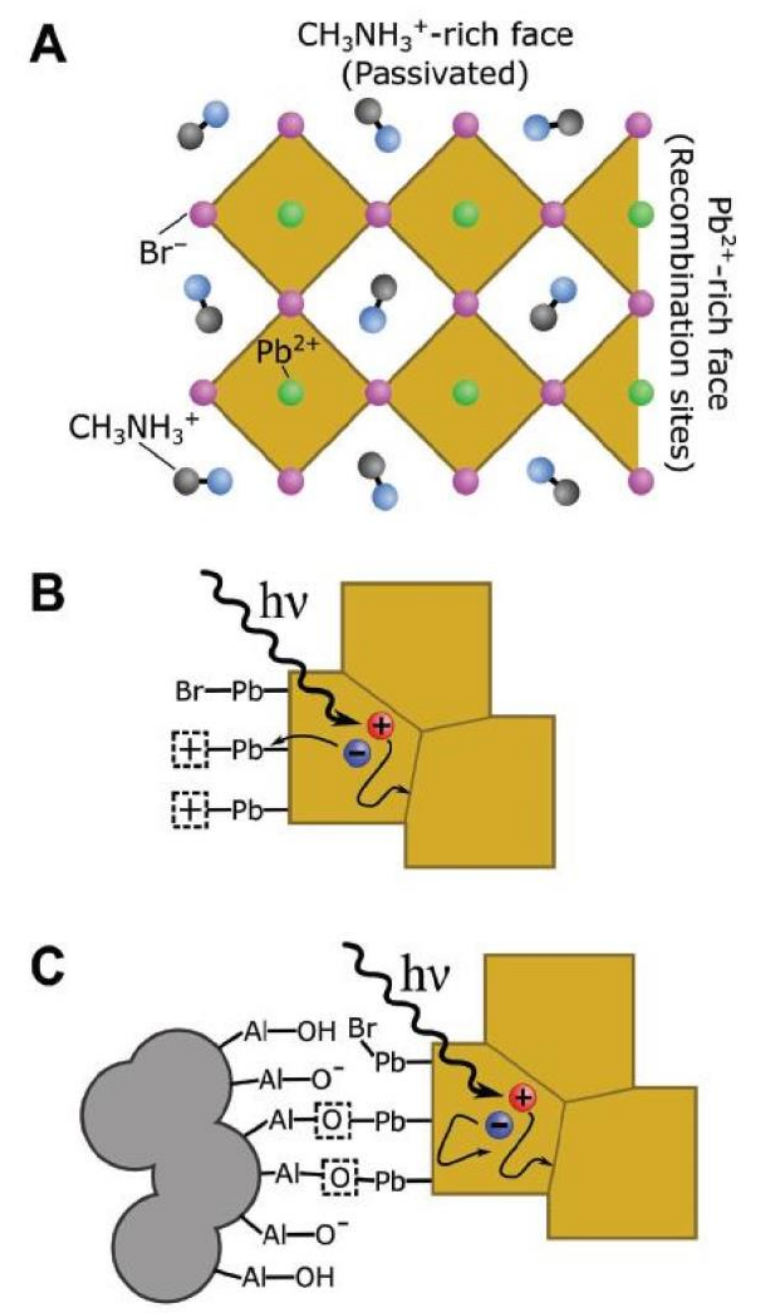

Figure 3. Possible mechanism of trap passivation in organic modified $\mathrm{Al}_{2} \mathrm{O}_{3}$ scaffold. Schematic representation of $\mathrm{A}$ ) different surface terminations in $\mathrm{MAPbBr} 3, \mathrm{~B})$ a $\mathrm{Pb}$-rich surface termination promoting electron trapping and/or surface recombination, and $\mathrm{C}$ ) surface passivation by intimate contact with mesoporous $\mathrm{Al}_{2} \mathrm{O}_{3}$. Reproduced with permission. ${ }^{[59]}$ Copyright 2018, Wiley VCH.

\section{Surface Functionalization to Improve Device Stability}

Initial works on the application of organic molecules as interfacial modifiers were aimed at enhancing device efficiency. Research works on device stability are still rare but an increasing number of published work can be found in the literature. A recent example is the dual modification of $\mathrm{ZnO}$ electron transport layer, first with a layer of another oxide, the $\mathrm{MgO}$ and second with a layer of ethylendiamine (EA)-functionalized $\mathrm{MgO}(\mathrm{MgO}-\mathrm{EA})$ (Figure 1c and 
1d). The resulting PSCs showed negligible hysteresis, high efficiency and high stability PSCs. The modification of the $\mathrm{ZnO}$ with the $\mathrm{MgO}-\mathrm{EA}$ permitted the reduction of the interface recombination improving efficiency and lifetime. The protonated EA promoted the effective electron transport from the perovskite to the $\mathrm{ZnO}$ electrode eliminating the hysteresis. The final PSC resulted in $21.1 \%$ efficiency, and the devices were stable in air for more than $300 \mathrm{~h}$ when graphene was applied as encapsulation. ${ }^{[13]}$ Special attention should be paid to the oxide properties and quality. For example, $\mathrm{ZnO}$ is basic in nature and can decompose halide perovskite through the deprotonation of the methylamine, leading to $\mathrm{PbI}_{2}$. The process seems to accelerate if any residue from the $\mathrm{ZnO}$ sol-gel starting solution is present (e.g. acetate ligands) or by the presence of surface hydroxyl groups. This decomposition mechanism is not observed in $\mathrm{TiO}_{2}$ due to its acidic properties. ${ }^{[60]}$ Recently, Jang, et al. reported the modification of the $\mathrm{ZnO}$ surface by highly polar molecules made as SAMs, with the objective of enhancing the hydrophobicity of the $\mathrm{ZnO}$, thereby improving the quality of halide perovskite crystallization. The SAM acted as a wetting control for $\mathrm{ZnO}$, as well as electric dipole layers, enhancing charge extraction. As a result, PSCs with $18.82 \%$ efficiency were obtained when a ZnO-SAMs electrode was applied, in contrast with the $15.41 \%$ efficiency obtained for the un-modified $\mathrm{ZnO}$ PSC. ${ }^{[61]}$

Figure 4 (also Figure 1e and 1f) shows the modification of two different oxide interfaces in a single PSC device. ${ }^{[14]}$ The modification of the interfaces was observed to improve PSC performance and stability. In this work, the authors applied, on the electron transport side, a $\mathrm{C}_{60}$-SAM molecule on top of the ITO electrode; and on the hole transport side, a polymer/TaWO interface. The phosphonic acid group of the $\mathrm{C}_{60}-\mathrm{SAM}$ molecule binds strongly to the oxide surface, and the highly conductive $\mathrm{Ta}-\mathrm{WO}_{\mathrm{x}}$ efficiently dopes the polymer layer, increasing hole transport and preventing device degradation. The final PSC configuration is 
ITO/C $60-\mathrm{SAM} /$ perovskite/PDCBT/Ta-WO $\mathrm{W} / \mathrm{Au}$, delivering a PCE of $21.2 \%$ with almost null hysteresis. The PSC showed more than $1000 \mathrm{~h}$ of stability under continuous illumination (unencapsulated, $\mathrm{N}_{2}$ atmosphere). When a compact $\mathrm{SnO}_{\mathrm{x}} / \mathrm{PC}_{60} \mathrm{BM}$ thin film was added on top of the $\mathrm{C}_{60}-\mathrm{SAM}$ molecule, the $\mathrm{V}_{\mathrm{oc}}$ increased up to $1.17 \mathrm{~V}$. The authors classified the polymer/Ta- $\mathrm{WO}_{\mathrm{x}}$ interface as universal, since the beneficial effect of the $\mathrm{Ta}-\mathrm{WO}_{\mathrm{x}}$ was observed for several polymers.

Large-scale solution processable printing methods compatible with polymer substrates are a key requirement for the fabrication and commercialisation of flexible PSCs. Nevertheless, the application of barrier layers made of organic molecules or polymers like PCBM, PEDOT:PSS or Spiro-OMeTAD, have been shown to be detrimental due to their instability towards humidity or light, or to their reactivity at interfaces. The replacement of these organic materials by metal oxides can be made at low temperature for flexible PSCs. Najafi, et al. demonstrated the application of $\mathrm{ZnO}$ and $\mathrm{NiO}$ nanoparticles as the ETL and HTL, respectively. The oxides were made as nanoparticles obtained by low temperature synthesis methods and were deposited on flexible substrates. The resulting PSC had the flexible configuration, $\mathrm{PEN} / \mathrm{ITO} / \mathrm{NiOx} \cdot \mathrm{np} /$ perovskite/PCBM/ZnO·np/Al (Figure 1r and 1s). The efficiencies obtained were as high as $18.6 \%$ for rigid devices and $16.6 \%$ for flexible devices. The devices showed less than a $15 \%$ efficiency decrease after $1000 \mathrm{~h}$ of testing under continuous irradiation. ${ }^{[25]}$ In this case, the oxide layers were applied without any interface modifier (or functionalization of the oxide surface), indicating possible room for improvement in efficiency and stability. These works demonstrate the advantage in efficiency and stability when metal oxides are applied as barrier layers, as well as the enhancement of device lifetime by the modification and functionalization of oxide interfaces. 
A

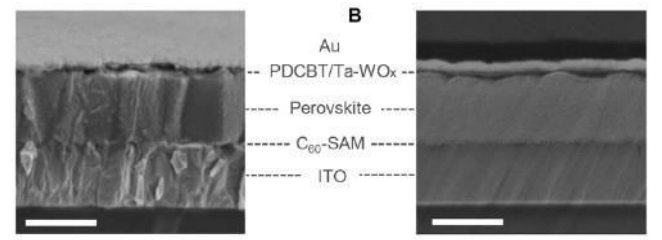

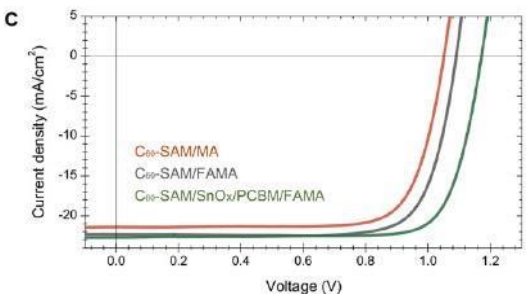

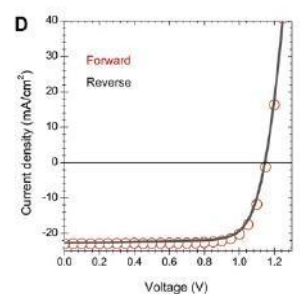

Voltage (v)

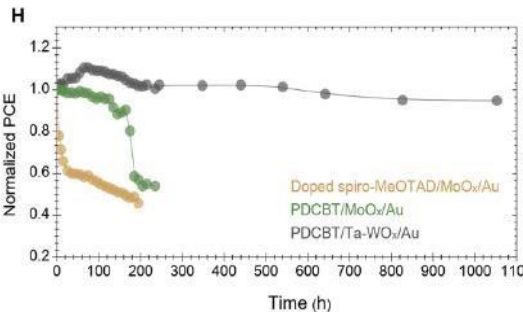

Voltage (n)
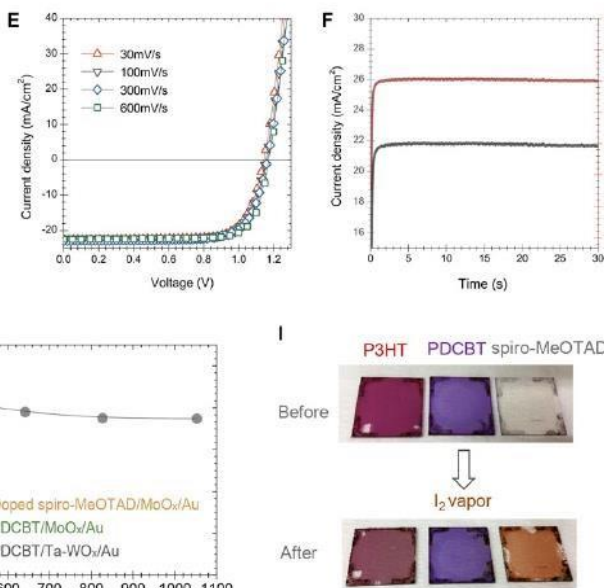
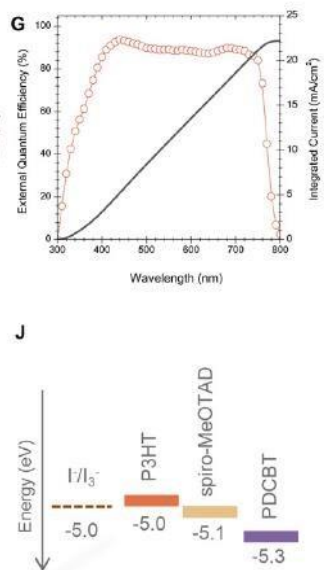

Figure 4. Perovskite solar cells applying two different oxides as transport layers with different oxide modification. (A) Scanning electron microscopy (SEM) image of crosssection of a complete perovskite device based on ITO/C 60 -SAM/Perovskite/PDCBT/TaWO $x / \mathrm{Au}$, the scale bar of $500 \mathrm{~nm}$. (B) Corresponding SEM image of a focused ion beam (FIB) polished crosssection, the scale bar of $500 \mathrm{~nm}$. (C) Corresponding $j-V$ curve of the maximized performance devices. The red curve represents Methyl ammonium (MA) perovskite using $\mathrm{C}_{60}$-SAM as ETM and PDCBT/Ta-WO $x$ as HTM, the black curve represents Formalidinium-Methyl ammonium (FAMA) perovskite based devices using $\mathrm{C}_{60}-\mathrm{SAM}$ as ETM and PDCBT/Ta-WO $\mathrm{P}_{x}$ as $\mathrm{HTM}$ and the green curve represents FAMA perovskite based devices using $\mathrm{C}_{60}-\mathrm{SAM} / \mathrm{SnO}_{x} / \mathrm{PC} 60 \mathrm{BM}$ as ETM and PDCBT/Ta-WO ${ }_{x}$ as HTM, the rate is kept at $300 \mathrm{mV} / \mathrm{s}$. (D) $j-V$ characteristics with different sweep directions. (E) $j$ - $V$ characteristics with different sweep speeds. (F) steady-state output at the maximum power point ( Vmpp of $0.97 \mathrm{~V}$ ) of the champion device under continuous simulated AM1.5G 1 sun illumination. (G) External quantum efficiency, EQE, of the champion device and the integrated current of $22.2 \mathrm{~mA} / \mathrm{cm}^{2}$. (H) Unencapsulated device photostability tests under continuous one sun illumination in a home-built chamber filled with $\mathrm{N}^{2}$. PCE variation of the HTM stacks based on a $\mathrm{C}_{60}-\mathrm{SAM}$ with a strong binding between the phosphonic acid to the oxide surface as ETM: spiro-MeOTAD/MoO $x / \mathrm{Au}$ (yellow), $\mathrm{PDCBT} / \mathrm{MoO} x / \mathrm{Au}$ (green) and PDCBT/Ta-WO $/ \mathrm{Au}$ (black). (I) Color variation of P3HT, PDCBT, and spiroMeOTAD single films on glass substrate before and after $\mathrm{I}_{2}$ vapor treatment. (J) the corresponding redox potential of $\mathrm{I}^{-} / \mathrm{I}^{3-}$ and the homo levels of P3HT, PDCBT, and spiroMeOTAD. Reproduced with permission ${ }^{[14]}$ Copyright 2018, Wiley VCH.

\section{Conclusion}


This work is a brief overview of some of the latest advances in the interfacial functionalization of oxide substrates and their effect on PSC performance and stability. The application of metal oxides in PSCs has been demonstrated to confer high stability to the solar cell device. The functionalization of oxide interfaces is a requisite for passivating defects and traps on the oxide surface and, in some cases, on the halide perovskite itself. Although the application of interface functionalization of oxides has been the focus of research for many years, the study of its effect on PSC stability is still infrequent, and more effort should be invested in this respect. The great variety of possible functional groups present in organic modifiers, together with the rich chemistry of metal oxides (both semiconductors and insulators), permits the design of novel functionalized oxide interfaces. The study and understanding of the effect of the functionalization of insulating scaffolds of $\mathrm{ZrO}_{2}$ or $\mathrm{Al}_{2} \mathrm{O}_{3}$ applied in C-based PSCs could lead to the development of more advanced and stable PSC configurations.

\section{Acknowledgements}

This work was carried out under the Materials Science Ph.D. Degree for A.M. of the Universitat Autònoma de Barcelona. H.-S.K. is grateful for the postdoctoral fellowship grant (NRF-2016R1A6A3A03012393); to the Spanish Ministry of Economy, Industry and Competitiveness (MINECO) through the Severo Ochoa Centers of Excellence Programme under Grant SEV-2013-0295; the grant ENE2016-79282-C5-2-R and the OrgEnergy Excelence Network CTQ2016-81911-REDT. To the Agència de Gestió d'Ajuts Universitaris i de Recerca (AGAUR) for the support to the consolidated Catalonia Research Group 2017 SGR-329 and the Xarxa de Referència en Materials Avançats per a l'Energia (Xarmae); and to the Centres de Recerca de Catalunya (CERCA) Programme / Generalitat de Catalunya and the European COST Action StableNextSol project MP1307. 
Received: ((will be filled in by the editorial staff))

Revised: ((will be filled in by the editorial staff))

Published online: ((will be filled in by the editorial staff))

\section{References}

[1] M. A. Green; Y. Hishikawa; E. D. Dunlop; J. Hohl-Ebinger; A. W. Ho-Baillie; et. al. Solar Cell Efficiency Table (Version 51). Prog. Photovoltaics 2018, 26, 3-12.

[2] Y. Reyna; A. Pérez-Tomás; A. Mingorance; M. Lira-Cantú. Stability of Molecular Devices: Halide Perovskite Solar Cells. In Molecular Devices for Solar Energy Conversion and Storage. Green Chemistry and Sustainable Technology.; Tian H., B. G., Hagfeldt A. (Eds) 2018; Springer Singapore.

[3] M. Setvin; M. Wagner; M. Schmid; G. S. Parkinson; U. Diebold. Chem. Soc. Rev. 2017, $46(7), 1772-1784$.

[4] S. Yang; Y. Wang; P. Liu; Y.-B. Cheng; H. J. Zhao; H. G. Yang. Nat. Energy 2016, 1, 15016.

[5] Y. Hou; S. Scheiner; X. Tang; N. Gasparini; M. Richter; N. Li; P. Schweizer; S. Chen; H. Chen; C. O. R. Quiroz; X. Du; G. J. Matt; A. Osvet; E. Spiecker; R. H. Fink; A. Hirsch; M. Halik; C. J. Brabec. Adv. Mater. Interf. 2017, 4 (11), 1700007.

[6] L. Zuo; Q. Chen; N. De Marco; Y.-T. Hsieh; H. Chen; P. Sun; S.-Y. Chang; H. Zhao; S. Dong; Y. Yang. Nano Lett. 2017, 17 (1), 269-275.

[7] N. Rolston; B. L. Watson; C. D. Bailie; M. D. McGehee; J. P. Bastos; R. Gehlhaar; J.-E. Kim; D. Vak; A. T. Mallajosyula; G. Gupta; A. D. Mohite; R. H. Dauskardt. Extr. Mech. Let. 2016, 9, 353-358.

[8] P. Zhao; B. J. Kim; H. S. Jung. Mater. Today Energ. 2018, 7, 267-286.

[9] M. Lira-Cantú. Nat. Energy 2017, 2 (7), nenergy2017115.

[10] G. Grancini; C. Roldán-Carmona; I. Zimmermann; E. Mosconi; X. Lee; D. Martineau; S. Narbey; F. Oswald; F. De Angelis; M. Graetzel; M. K. Nazeeruddin. Nat. Commun. 
2017, 8, 15684.

[11] J. You; L. Meng; T.-B. Song; T.-F. Guo; Y. Yang; W.-H. Chang; Z. Hong; H. Chen; H. Zhou; Q. Chen; Y. Liu; N. De Marco. Nat Nano 2016, 11 (1), 75-81.

[12] Y. Wang; T. Mahmoudi; W.-Y. Rho; H.-Y. Yang; S. Seo; K. S. Bhat; R. Ahmad; Y.-B. Hahn. Nano Energy 2018, 49, 59-66.

[13] C. Jing; W. Binghui; C. Ruihao; W. Youyunqi; H. Yong; M. Bing_Wei; Z. Nanfeng. Adv. Mater. 2018, 30 (11), 1705596.

[14] Y. Hou; X. Du; S. Scheiner; D. P. McMeekin; Z. Wang; N. Li; M. S. Killian; H. Chen; M. Richter; I. Levchuk; N. Schrenker; E. Spiecker; T. Stubhan; N. A. Luechinger; A. Hirsch; P. Schmuki; H.-P. Steinrück; R. H. Fink; M. Halik; H. J. Snaith; C. J. Brabec. Science 2017, 358, 1192-1197.

[15] D. H. Sin; S. B. Jo; S. G. Lee; H. Ko; M. Kim; H. Lee; K. Cho. ACS Appl. Mater. Interf. 2017, 9 (21), 18103-18112.

[16] W. Chen; Y. Wu; Y. Yue; J. Liu; W. Zhang; X. Yang; H. Chen; E. Bi; I. Ashraful; M. Grätzel; L. Han. Science 2015, 350 (6263), 944-948.

[17] H. Back; G. Kim; J. Kim; J. Kong; T. K. Kim; H. Kang; H. Kim; J. Lee; S. Lee; K. Lee. Energ. Env. Sci. 2016, 9 (4), 1258-1263.

[18] A. Bashir; S. Shukla; J. H. Lew; S. Shukla; A. Bruno; D. Gupta; T. Baikie; R. Patidar; Z. Akhter; A. Priyadarshi; N. Mathews; S. G. Mhaisalkar. Nanoscale 2018, 10 (5), 23412350.

[19] Y. Li; Y. Zhao; Q. Chen; Y. Yang; Y. Liu; Z. Hong; Z. Liu; Y.-T. Hsieh; L. Meng; Y. Li; Y. Yang. J. Am. Chem. Soc., 2015, 137 (49), 15540-15547.

[20] S. S. Shin; E. J. Yeom; W. S. Yang; S. Hur; M. G. Kim; J. Im; J. Seo; J. H. Noh; S. I. Seok. Science 2017, 365 (6334), 167-171.

[21] O. Dan; X. Junyan; Y. Fei; H. Zhanfeng; Z. Hong; Z. Lu; C. Jiaqi; C. W. C. H. $A d v$. Energ. Mater. 2018, 8 (16), 1702722. 
[22] C.-Y. Chang; W.-K. Huang; J.-L. Wu; Y.-C. Chang; K.-T. Lee; C.-T. Chen. Chem. Mater. 2016, 28 (1), 242-251.

[23] J. H. Kim; P.-W. Liang; S. T. Williams; N. Cho; C.-C. Chueh; M. S. Glaz; D. S. Ginger; A. K. Y. Jen. Adv. Mater. 2015, 27 (4), 695-701.

[24] P.-L. Qin; H.-W. Lei; X.-L. Zheng; Q. Liu; H. Tao; G. Yang; W.-J. Ke; L.-B. Xiong; M.C. Qin; X.-Z. Zhao; G.-J. Fang. Adv. Mater. Interf. 2016, 3 (14), 1500799.

[25] N. Mehrdad; D. G. Francesco; Z. Dong; S. Santhosh; S. Alessia; V. Wiljan; H. Afshin; G. Yulia; A. Tom; V. Sjoerd; A. Ronn. Small 2018, 14 (12), 170277.

[26] W. Ying_Chiao; L. Xiaodong; Z. Liping; L. Xiaohui; Z. Wenjun; F. Junfeng. Adv. Energ. Mater. 2017, 7 (21), 1701144.

[27] A. Hagfeldt; M. Lira-Cantu. Appl. Surf. Sci. 2018, In Press.

[28] S. P. Pujari; L. Scheres; A. T. M. Marcelis; H. Zuilhof. Ang. Chem. Intl. Ed. 2014, 53 (25), 6322-6356.

[29] J. C. Wang; K. Violette; O. O. Ogunsolu; S. Cekli; E. Lambers; H. M. Fares; K. Hanson. Lang. 2017, 33 (38), 9609-9619.

[30] M.-A. Neouze; U. Schubert. Monatshefte Chemie - Chem.Mont. 2008, 139 (3), 183-195.

[31] A. Perez-Tomas; A. Mingorance; Y. Reyna; M. Lira-Cantu. Metal Oxides in Photovoltaics: All-Oxide, Ferroic, and Perovskite Solar Cells. In The Future of Semiconductor Oxides in Next Generation Solar Cells; Lira-Cantu, M., Ed.; Elsevier: 2017; Chapter 11, p 566.

[32] M. Lira-Cantu. The future of semiconductor oxides in next generation solar cells, 1st ed.; Elsevier: 2017; p 566.

[33] S. Meng; E. Kaxiras. Nano Lett. 2010, 10 (4), 1238-1247.

[34] M. T. Greiner; M. G. Helander; W.-M. Tang; Z.-B. Wang; J. Qiu; Z.-H. Lu. Nat. Mater. 2011, 11, 76 .

[35] R. Qiao; L. Zuo. J. Mater. Res. 2018, 33 (4), 387-400. 
[36] P. Topolovsek; F. Lamberti; T. Gatti; A. Cito; J. M. Ball; E. Menna; C. Gadermaier; A. Petrozza. J. Mater. Chem. A 2017, 5 (23), 11882-11893.

[37] X. Li; M. Ibrahim Dar; C. Yi; J. Luo; M. Tschumi; S. M. Zakeeruddin; M. K. Nazeeruddin; H. Han; M. Grätzel. Nat. Chem. 2015, 7 (9), 703-711.

[38] S. K. Hau; H.-L. Yip; K.-S. Chen; J. Zou; A. K.-Y. Jen. Appl. Phys. Lett. 2010, 97 (25), 253307.

[39] M. Song; J.-W. Kang; D.-H. Kim; J.-D. Kwon; S.-G. Park; S. Nam; S. Jo; S. Y. Ryu; C. S. Kim. Appl. Phys. Lett. 2013, 102 (14), 143303.

[40] Ç. Kırbıyı; K. Kara; D. A. Kara; M. Z. Yiğit; B. İstanbullu; M. Can; N. S. Sariciftci; M. Scharber; M. Kuş. Appl. Surf. Sci. 2017, 423, 521-527.

[41] S. Das; J. Joslin; T. L. Alford. Sol. Energy. Mater. Sol. Cells. 2014, 124, 98-102.

[42] Y.-Q. Wang; S.-B. Xu; J.-G. Deng; L.-Z. Gao. R Soc Open Sci. 2017, 4 (12), 170980.

[43] M. Valles-Pelarda; B. C. Hames; I. García-Benito; O. Almora; A. Molina-Ontoria; R. S. Sánchez; G. Garcia-Belmonte; N. Martín; I. Mora-Sero. J. Phys. Chem. Lett. 2016, 7 (22), 4622-4628.

[44] B. Li; Y. Chen; Z. Liang; D. Gao; W. Huang. RSC Adv. 2015, 5 (114), 94290-94295.

[45] Q. Wang; C.-C. Chueh; T. Zhao; J. Cheng; M. Eslamian; W. C. H. Choy; A. K. Y. Jen. ChemSusChem 2017, 10 (19), 3794-3803.

[46] Y. Bai; Q. Dong; Y. Shao; Y. Deng; Q. Wang; L. Shen; D. Wang; W. Wei; J. Huang. Nat. Commun. 2016, 7, 12806.

[47] L. Liu; A. Mei; T. Liu; P. Jiang; Y. Sheng; L. Zhang; H. Han. J. Am. Chem. Soc. 2015, $137(5), 1790-1793$.

[48] K. Wojciechowski; S. D. Stranks; A. Abate; G. Sadoughi; A. Sadhanala; N. Kopidakis; G. Rumbles; C.-Z. Li; R. H. Friend; A. K. Y. Jen; H. J. Snaith. ACS Nano 2014, 8 (12), 12701-12709.

[49] X. Liu; K.-W. Tsai; Z. Zhu; Y. Sun; C.-C. Chueh; A. K. Y. Jen. Adv. Mater. Interf. 2016, 
$3(13), 1600122$.

[50] L. Zuo; Z. Gu; T. Ye; W. Fu; G. Wu; H. Li; H. Chen. J. Am. Chem. Soc. 2015, 137 (7), 2674-2679.

[51] X. Hou; S. Huang; W. Ou-Yang; L. Pan; Z. Sun; X. Chen. ACS App. Mater. Interf. 2017, 9 (40), 35200-35208.

[52] X. Zhang; G. Wu; W. Fu; M. Qin; W. Yang; J. Yan; Z. Zhang; X. Lu; H. Chen. Adv. Energ. Mater. 2018, 8 (14), 1702498.

[53] Y. Xu; B. Feng; M. Xue; Z. Li; Q. Xiong; J. Zhang; J. Duan; X. Wang; H. Wang. Int. J. Energ. Res. 2017, 41 (13), 1847-1854.

[54] J. Ciro; S. Mesa; J. I. Uribe; M. A. Mejia-Escobar; D. Ramirez; J. F. Montoya; R. Betancur; H.-S. Yoo; N.-G. Park; F. Jaramillo. Nanoscale 2017, 9 (27), 9440-9446.

[55] H. n. Bedis. J. Surf. Sci. Eng. Mater. Adv. Tech. 2011, Vol.01No.02, 9.

[56] M. Maniruzzaman; C. H. Lim; K. Yang; C. Lee; H.-S. Nam; J. Lee. J. Nanosc. Nanotech. 2014, 14 (10), 7779-7783.

[57] Y. Hou; C. O. R. Quiroz; S. Scheiner; W. Chen; T. Stubhan; A. Hirsch; M. Halik; C. J. Brabec. Adv. Energ. Mater. 2015, 5 (20), 1501056.

[58] A. Mei; X. Li; L. Liu; Z. Ku; T. Liu; Y. Rong; M. Xu; M. Hu; J. Chen; Y. Yang; M. Grätzel; H. Han. Science 2014, 345 (6194), 295-298.

[59] R. Godin; X. Ma; S. González-Carrero; T. Du; X. Li; C.-T. Lin; M. A. McLachlan; R. E. Galian; J. Pérez-Prieto; J. R. Durrant. Adv. Opt. Mater. 2018, 6 (5), 1701203.

[60] J. Yang; B. D. Siempelkamp; E. Mosconi; F. De Angelis; T. L. Kelly. Chem. Mater. 2015, 27 (12), 4229-4236.

[61] A. Randi; H. W. Tantyo; S. Septy; L. Chang_Lyoul; Y. S. Cheol; J. I. Hwan; J. Sung_Yeon. Adv. Energ. Mater. 2018, 8 (5), 1701683. 